\title{
THE IMPACT OF ACIDIFICATION ON DIATOMS AND CHEMISTRY OF DUTCH MOORLAND POOLS
}

\author{
HERMAN VAN DAM
}

(Research Institute for Nature Management, P.O.Box 46, 3956 ZR Leersum, the Netherlands)

\section{GILLIS SUURMOND}

(Nature Conservation Department, Agricultural University, P.O.Box 8080, 6700 DD Wageningen, the Netherlands)

\section{CANO TER BRAAK}

(Institute T.N.O. for Mathematics, Information Processing and Statistics, P.O.Box 100,6700 AC Wageningen, the Netherlands)

\section{(SUMMARY)}

Moorland pools are shallow oligotrophic soft water lakes on poorly buffered sandy soils. Diatom assemblages of samples from 16 pools taken in 1920 and 1978 were compared by analysis of pH-spectra, diversity, dissimilarity and multivariate statistical techniques.

The $\mathrm{pH}$-spectra of pools in the southern $(\mathrm{S})$ and central $(\mathrm{C})$ part of the country indicate a fall in $\mathrm{pH}$ from $4.5-6.0$ in the old samples to $3.7-4.6$ in the recent ones. The pH-spectra of the northern pools (N) do not indicate a significant shift from the original $\mathrm{pH}$ ( $\mathrm{ca} 4.5$ ).

The number of species in the count and the diversity (indices of Simpson and Shannon) decreased significantly in S+C, and that goes also for the dissimilarity index of Dyer. No changes were found in $\mathrm{N}$.

The first component (PC 1) of the principal component analysis explains $61 \%$ of total variance. PC 1 is correlated with $\log \left[\mathrm{SO}_{4}\right] \quad(r=0.83, p<0.001)$ and even better $(r=0.95, p<0.001)$ with the relative sulphate concentration, i.e. the ratio of sulphate to all major anions (sulphate, chloride, bicarbonate). All old samples have low scores on PC 1, recent samples have low scores on the second (PC 2) and third (PC 3) principal component. Old samples have high scores on PC 2 and PC 3, explaining 9 and $6 \%$ of total variance, respectively.

The orginal variation, caused by regional factors, is replaced by a $\mathrm{SO}_{4}{ }^{2}$ controlled variation. PC 1 is nearly completely determined by the relative abundance of Eunotia exigua. This species, which is known to be very resistant to pollution by sulphur, aluminium and heavy metals, increased largely from 1920 to 1978.

In spite of the rather homogeneous distribution of wet sulphate deposition in the Netherlands, substantial differences in $\mathrm{SO}_{4} 2$-content in the pools are observed, being lowest in $\mathrm{N}\left(0.13-0.48\right.$ meq. $\left.1^{-1}\right)$ and highest in $S+C\left(0.38-1.65\right.$ meq. $\left.I^{-1}\right)$. Sulphate is positively correlated with calcium, aluminum and magnesium but negatively with factors that characterize humic acid waters (e.g. permanganate-consumption, iron and the ratio of univalent to divalent cations). Sulphate concentration depends on the intensity of sulphate reduction, accumulation by dry deposition in surrounding forests of Scots pine, drought and atmospheric deposition.

\section{DIEL PATTERNS OF PHYTOPLANKTON PRODUCTIVITY IN LAKE VECHTEN}

\section{W.OPSTELTEN}

(Limnological Institute, Vijverhof Laboratory, Nieuwersluis (U.), The Netherlands)

\section{(SUMMARY)}

A review of the literature on phytoplankton primary production studies in lakes indicates that in most cases the daily primary production rates have been derived by multiplying the short-term lusually 3 or 4 hours) production measurement with a light factor. This factor is a ratio between the total irradiance during the day and during the period of incubation. The aim of the present study was to verify this method of calculation. Since the primary production rate is of great importance for the carbon cycle of lakes, this study can be regarded as a fundamental contribution to the integrated research of the ecosystem of lake 